\title{
تصميم عرض أزياء افتراضي باستخدام البراهج الثلاثية الأبعاد
}

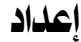 \\ أ. حليمة محمد مشاركي الراشديكي \\ ماجستير بقسم الملابس والنسيج كلية الاقتصاد المنزلي - جامعة الملك عبد العزيز بجدة المالية \\ ومعيد بقسم التربية الأسرية الكلية الجامعية بالقنفذة ، جامعة أم القرى \\ د. آمالـ عبد القادر باصفار

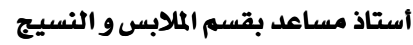

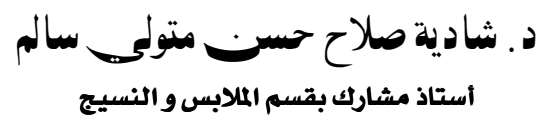

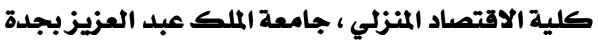

كلية الاقتصاد المنزلي ، جامعة الملك عبد العزيزبجدة

مجلة بحوث التربية النوعية ـ جامعة المنصورة

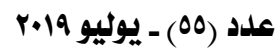




\section{تهميم عرض أزياء افتزاضي باستخدام البرامجه الثلاثية الأبعاد}

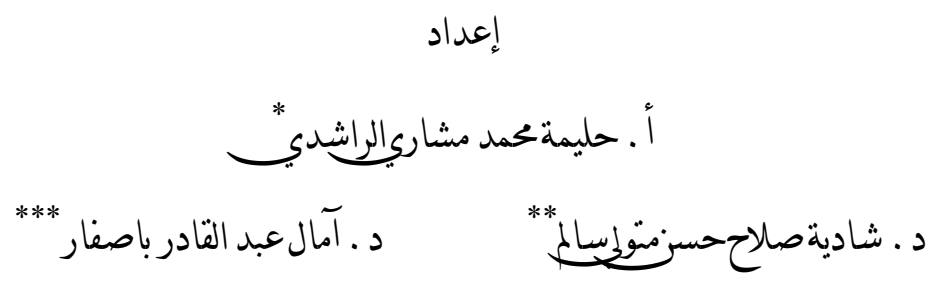

טגil|

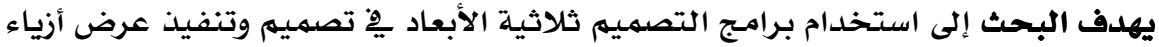

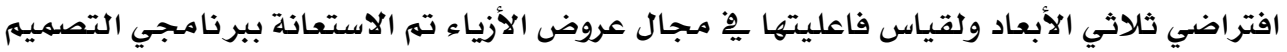
(3D Max) لتصميم الأزياء وبرنامج (Marvelous Designer 3) وبرنامجج (Movie Maker) لإخراج العرض بشكلهه النهائي.

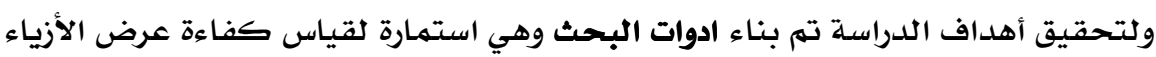

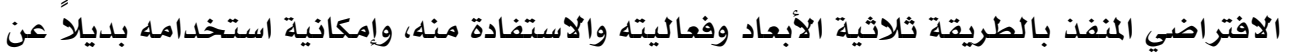

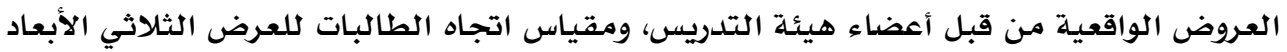

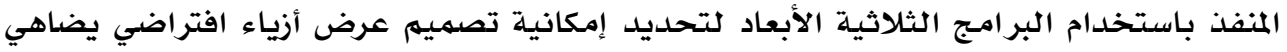

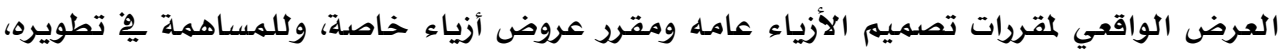

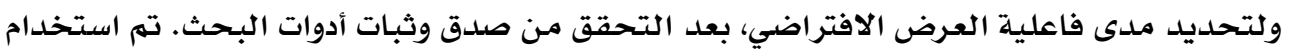

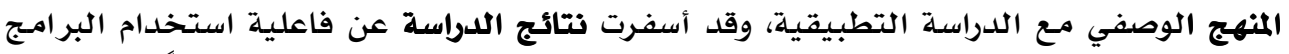

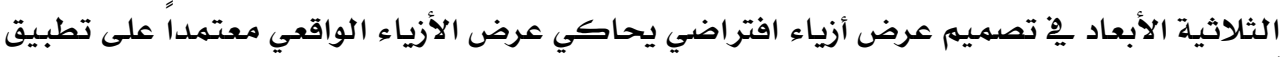

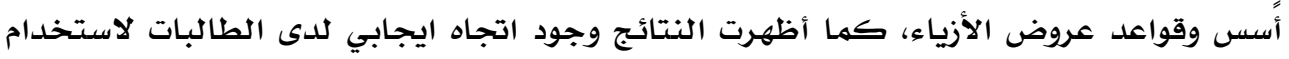

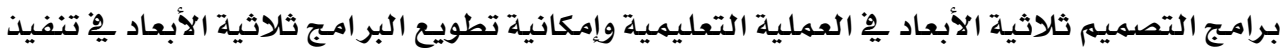

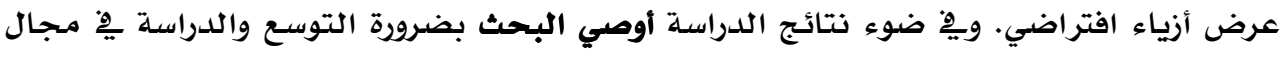

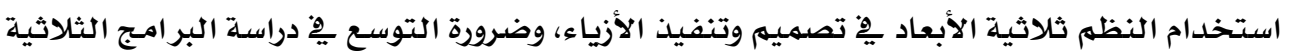

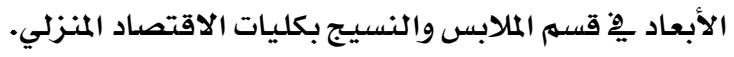
كلمات مرجعية Keywords:

Fashion Show, Three-dimensional design, Three-dimensional garment, Fashion industry, Virtual Fashion Show

"ماجستير بقسم الملابس والنسيج كلية الاقتصاد المنزلي -جامعة الملك عبد العزيز بجدة

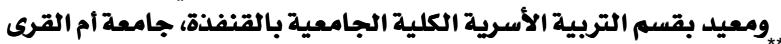

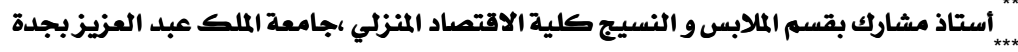

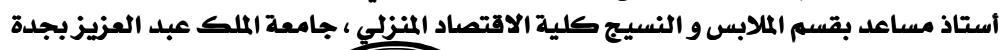


الاقدمهة Introduction

مـع التقدم التكنولوجي وتطوره السريع عِّ حياة الصناعة المعاصرة عامـة وِِّ صناعة الأزياء

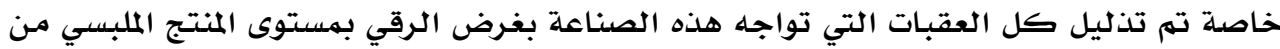

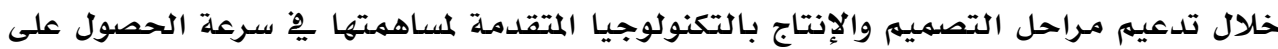

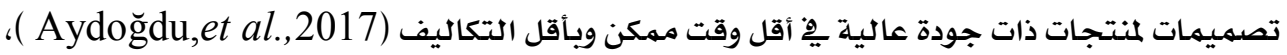

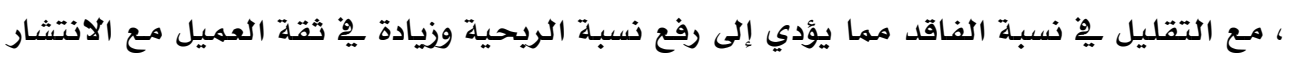

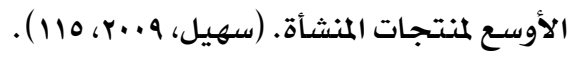

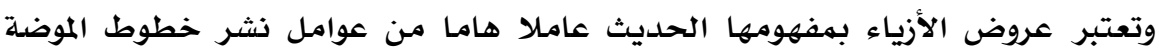

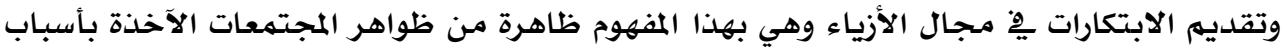

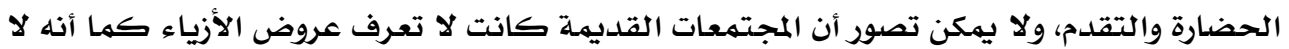

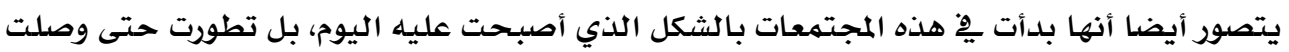

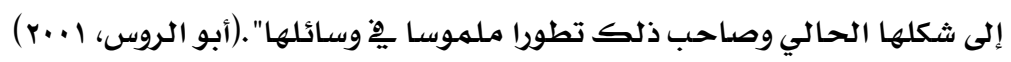

فإذا تم إنتاج هذه العروض بطريقة فنية فإن العرض يحقق نجاحا كبيرا للهصمهم

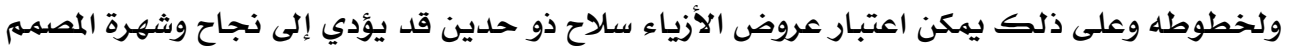

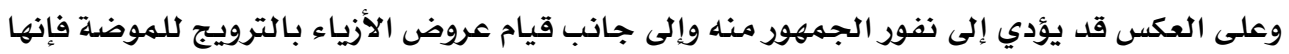

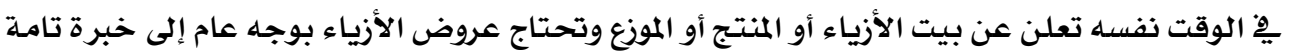

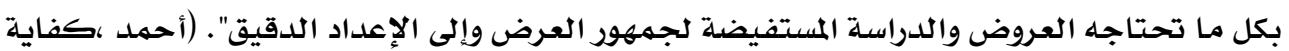

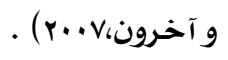

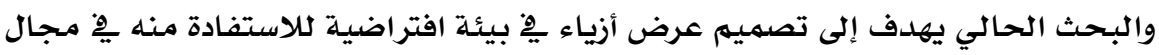

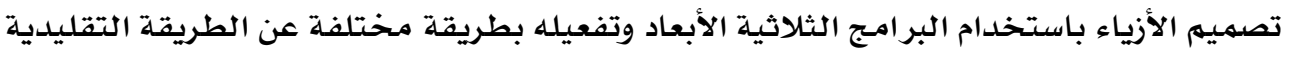

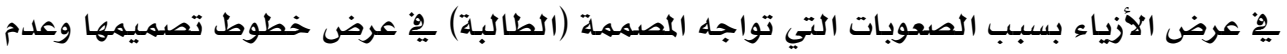

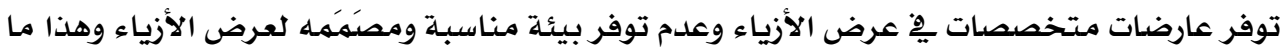

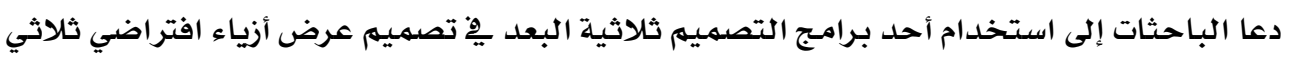
الأبعاد.

نظراً لندرة الدراسات التي تتناول مجال عروض الأزياء الافتراضية ثلاثية الأبعاد

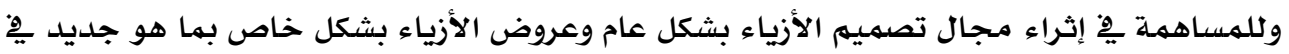

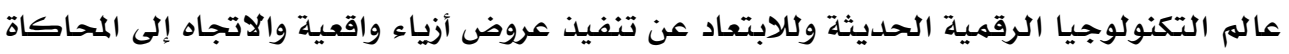

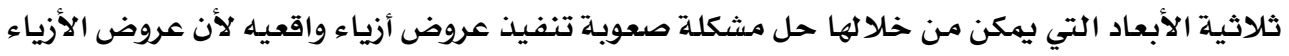

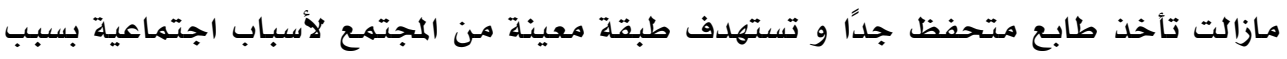

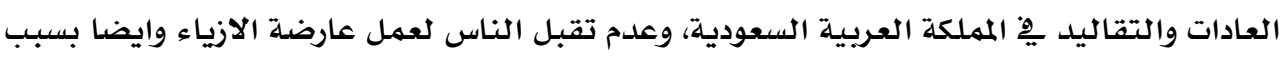

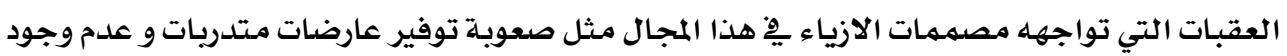




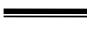

تصاريح رسمية لمثل هذا النشاط وعدم امكانية الاعلان عن عروض الازياء بشكل مباشر ؛ وجدات

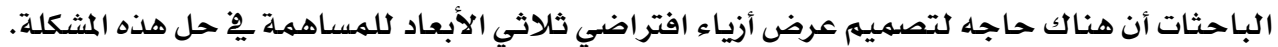

:Statement of the problem مشكلة البـث

\section{ويناء على ما سبق يمكن صياغة مشكلة البحث ِِّ التساؤلات التالية:}

$$
\text { ا ـ ما إمكانية تصميه عرض أزياء افتراضي ثلاثي الأبعاد : }
$$

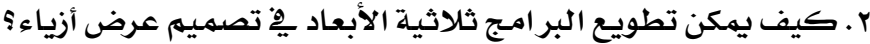

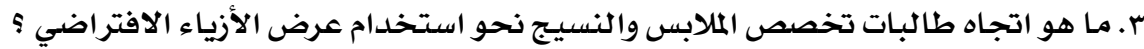

\section{أهد|فه البمث Objectives:}

تهدف هذه الدراسة إلى:

1. الاستفادة من إمكانات البر امج ثلاثية الأبعاد يِّ تصميم عرض أزياء.

$$
\text { r. r. تصميم عرض أزياء افتراضي ثلاثي الأبعاد. }
$$

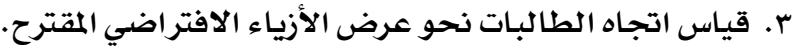

: Significance

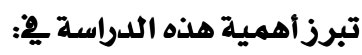

ا ـ المساهمة هِّ ابراز أهمية عروض الأزياء كوسيلة إعلانية وتسويقية. r. المسـاهمة إثراء مجال تصميم الأزياء بالاستفادة مـن التقنيـات الحديثة للتكنولوجيـا الرقميـة ومن ثم الارتقاء بالصناعة داخل المملكة.

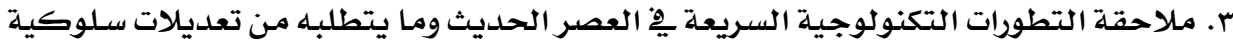
ومهاريـة وتنميلة قدرات.

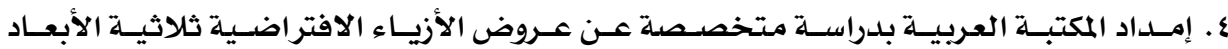
والاستفادة منها يِّ إثراء النواحي الابتكارية لمجالات الأزياء.

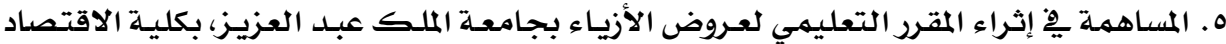

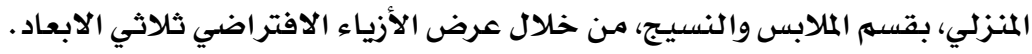

فروض البهث Hypothesis: فاعليـة و كفـاءة البر امـج ثلاثيـة الأبعـاد (3D) فِ تصميم عـرض أزيـاء افتراضـي يمكن اثباتها من خلال الفروض التالية :

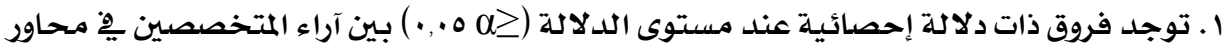
عرض الأزياء الافتراضي. 


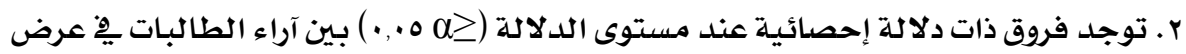

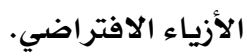

r. يوجد اتجاه إيجابي لدى الطالبات نحو استخدام عروض الأزياء الافتراضية.

:Terminology إلصطات

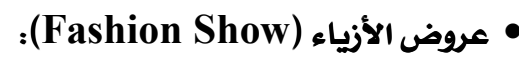

هو النشاط الترويجي الوحيد الذي يقدم السلعة على شخص فعلي ، أي يقدم السلعة كمها

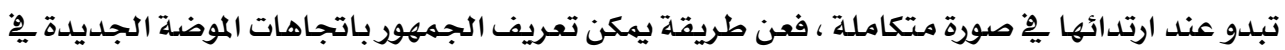

الخطوط والألوان والمكمل (Dark et al., 1992)

وتعرفه الباحثات بأنه: وسيلة أو طريقة يهكن من خلالها عرض مجموعة من التصميمات

والأزياء بشكل منسق وبمعايير محدده.

• برامج التصميم ثلاثي الأبعاد (Three-dimensional Design Programs):

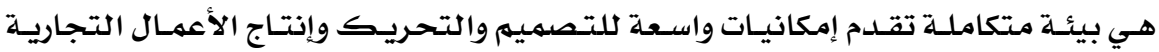

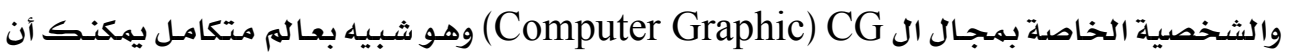

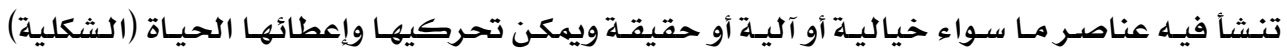

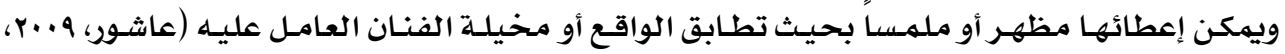

.(Elizabeth \&Ellen, 2010) \&( १

• الواقع الافتراضي (Virtual Reality)؛

بيئة متكاملة تجمع وتدار بواسطة برنامـج حاسوبي، حيث يدخل المتعلم فيه البيئة التعليمة

ويتفاعل معها. (Jun et al.,2017), (Brown\&Gordon,2008)

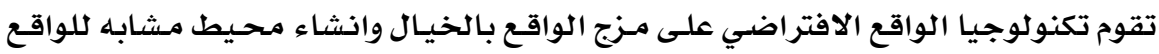

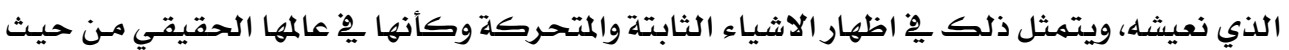

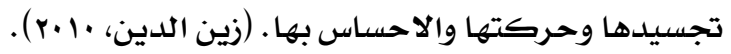

هنهج البحث Methodology:

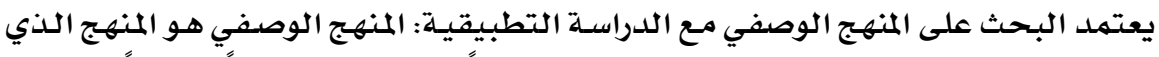

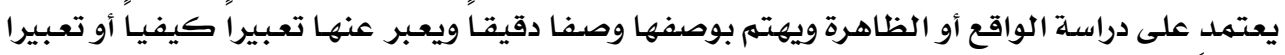

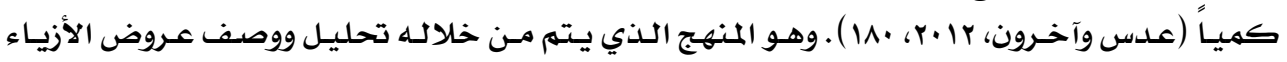

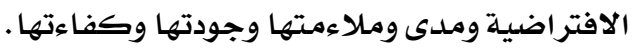

\section{هدود البمث:}

ا ـ اقتصرت حسدود البحث على تصميم وتنفيـذ عرض أزيـاء افتر اضـي باستخدام البر امـج ثلاثيـة 


\section{• برنامج 3 Marvelous Designer}

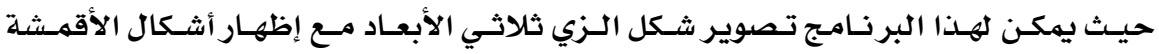

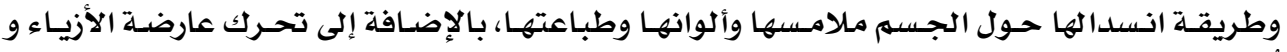

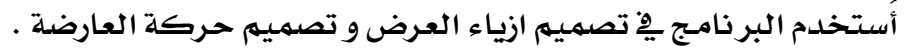

$$
\begin{aligned}
& \text { • برنامج التصميم }
\end{aligned}
$$

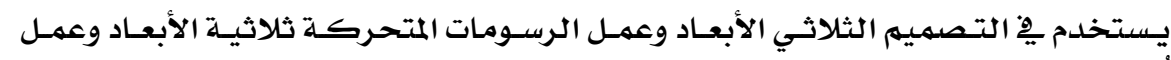

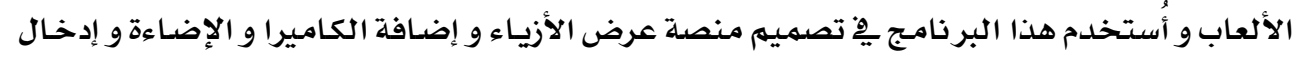
العارضة وتسجيل حركتها ِِّ صيغة فيديو.

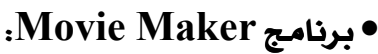

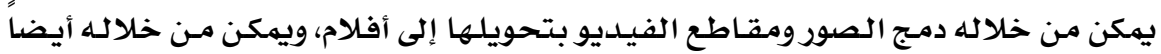

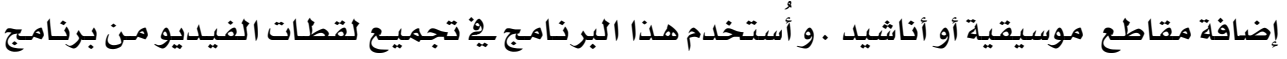
3D max

\section{عينة الدراسة Sample:}

تكوَّنت عينة البحث من ( .0) طالبه من كليات الاقتصساد المنزلي بجامعة الملك عبد العزيز

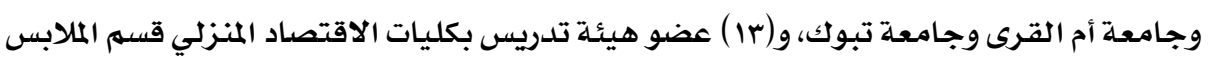

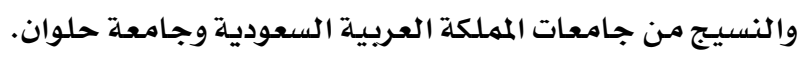

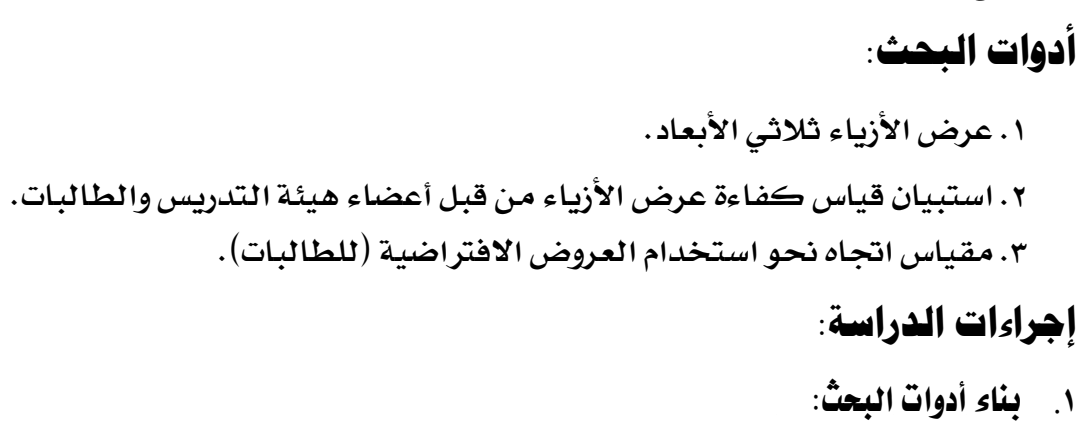

أولا : إعلاد استبيان لقياس الكفاءة الفنية لعرض الأزياء ثلاثي الأبعاد:

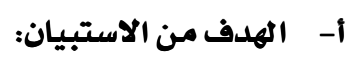

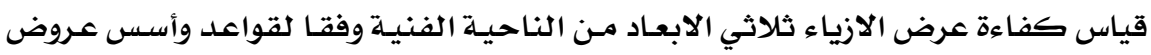

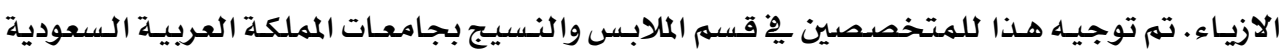




\section{تصمير عرض أزياء /فتراضي باستخدام البرامج الثلاثية الأبعاد

$$
\text { ب- إعداد ووصف الاستبيان: }
$$

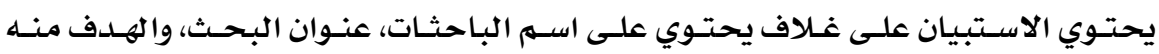

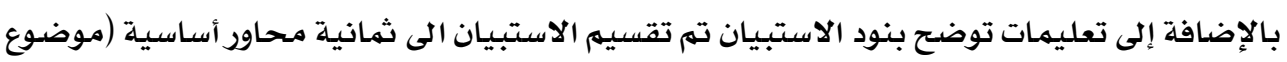

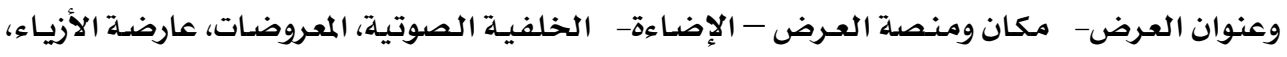

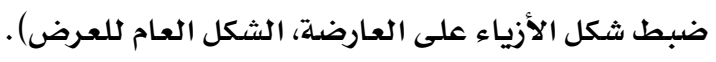
ج- عليمات الاستبيان:

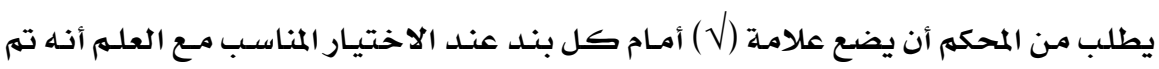

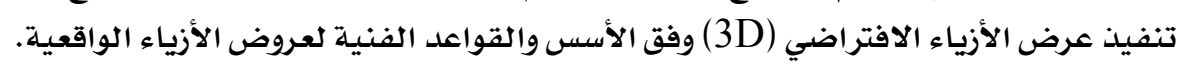
د- تصحيح الاستبيان:

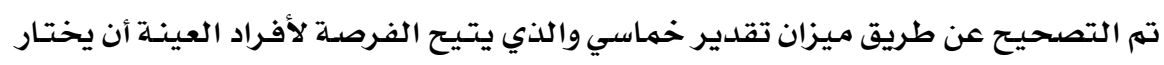

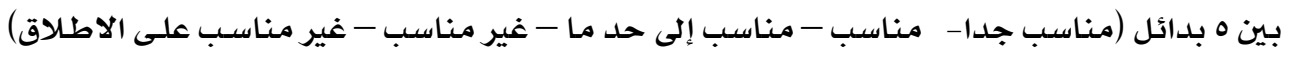

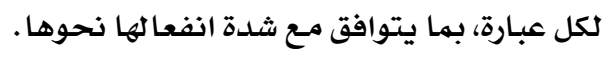

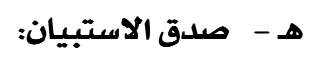

بعد الانتهاء من إعداد استبيان قياس كفاءة عرض الأزياء الافتراضي المنفذ بالطريقة

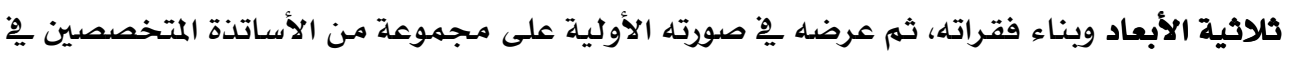

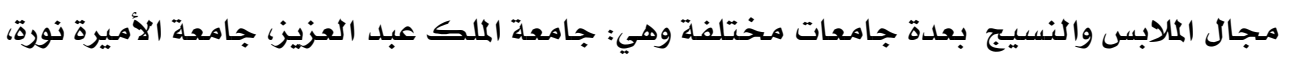

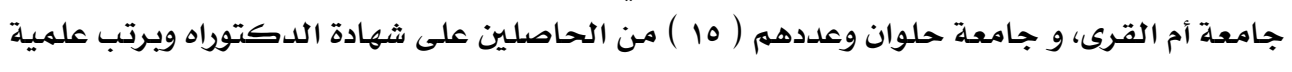
مختلفة، للتأكد من مأفرى و جامع • مدى ارتباط كل فقرة من فقرات كل الاستبيان بالمجموع الكلي للفقرات

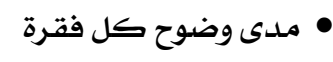

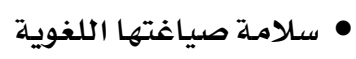
• ملاءمتها لتحقيق الهدف الذي وضعت من ألغوية أجله

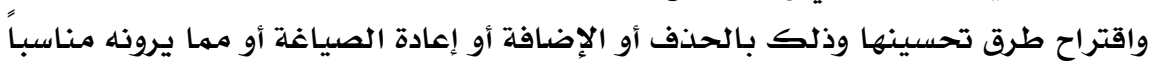
وفيما يلي نسب الاتفاق بين المحكمين فيما يخص بنود تحكيم أدوات البحث :- 
جدول رقم (1) نسب الاتفاق بين المحكمين لبنود التحكيم لاستبيان قياس كفاءة عرض الأزياء

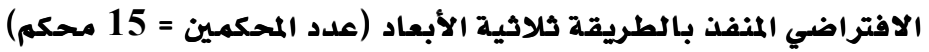

\begin{tabular}{|c|c|c|c|c|}
\hline \multicolumn{3}{|c|}{ استبيان قياس كفاءة عرض الأزياء } & \multirow{2}{*}{ بنود التحكيي } & \multirow{2}{*}{ ค } \\
\hline نسبة الاتفاق & علد مرات الاختلاف & علد مرات الاتفاق & & \\
\hline 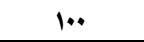 & - & 10 & صحة تقسيي المحاور & 1 \\
\hline $94, r$ & 1 & $1 \varepsilon$ & مناسبة المحاور & $r$ \\
\hline $1 \cdots$ & - & 10 & ارتباط العبارات بالمحور التابع لها & $r$ \\
\hline Av & $r$ & ir & دقة صياغة عبارات كل محور & $\xi$ \\
\hline $1 \cdots$ & $\cdot$ & 10 & صحة وسهولة الصياغة اللفظية & 0 \\
\hline$\% 97$ & \multicolumn{4}{|c|}{ إجمالي البنود } \\
\hline
\end{tabular}

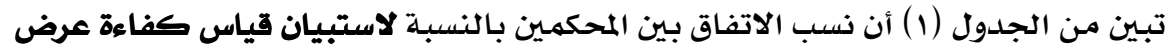

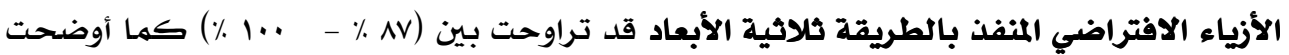

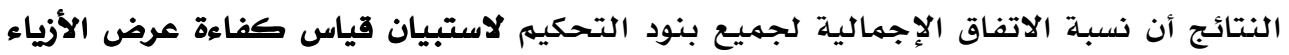

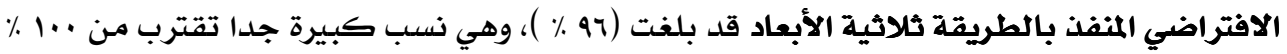

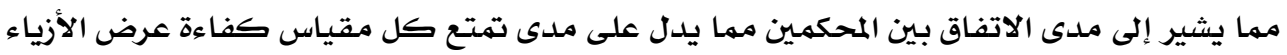

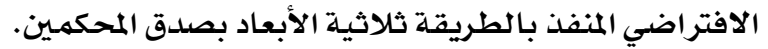

و- صدق الاتساق الداخلي لاستبيان قياس كفاءة عرض الأزيـاء الافتراضي المنفذ بالطريقة ثلاثية الأبعاد:

تم التأكد من صدق الاتساق الداخلي لاستبيان قياس كفاءة عرض الأزياء الافتراضي

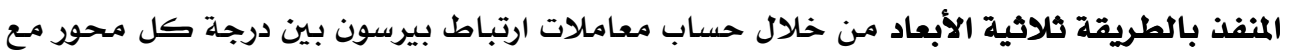

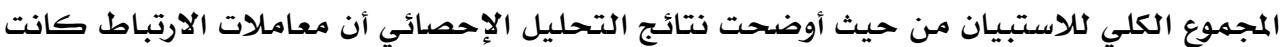

جدول رقم (2) معاملات ارتباط بيرسون بين درجة كل محور والمجموع الكلي للمحاور

\begin{tabular}{|c|c|}
\hline معامل ارتباط بيرسوز & 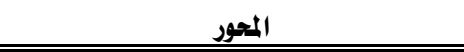 \\
\hline$* *, q$ & المحور الأول / موضوع وعنوان العرض \\
\hline$* *, 9 r$ & المحور الثاني / مكان ومنصة العرض \\
\hline$* *$, * 10 & المحور الثالث / الإضاءة \\
\hline$* *, 9 r$ & المحور الرابع / الخلفية الصوتية \\
\hline$* *, \wedge r$ & المحور الخامس / المعروضات \\
\hline$* *_{\bullet}, \wedge \wedge$ & المحور السادس / عارضة الأزياء \\
\hline$* *, \wedge \mathrm{r}$ & المحور السابع / ضبط شكل الأزياء على العارضة \\
\hline$* *, 91$ & المحور الثامن / الشكل العام للعرض \\
\hline
\end{tabular}

** معامل الارتباط دال إحصائيا عند مستوى دلالة ا .,.. 
من الجدول السابق اتضـح أن معاملات ارتباط بيرسون بين درجة كل محور مـن محاور

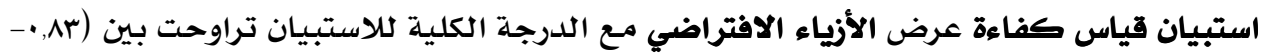

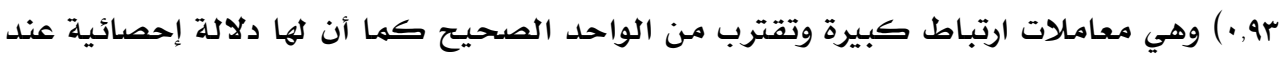

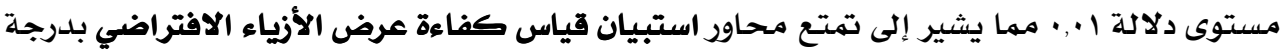

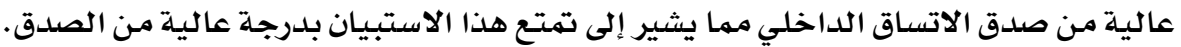
ز- مبات المقياس:

لحساب ثبات استبيان قياس كفاءة عرض الأزياء الافتراضي تم استخدام طريقة ألفا-

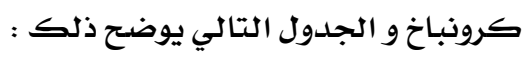
جدول رقم (3) نتائج معاملات الثبات الفا كرونباخ لاستبيان قياس كفاءة عرض الأزياء

\begin{tabular}{|c|c|}
\hline معامل ثبات الفا كرونباخ & 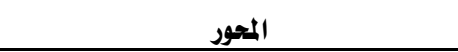 \\
\hline$\bullet, 97$ & المحور الأول / موضوع وعنوان العرض \\
\hline$\cdot, \wedge \mathrm{V}$ & المحور الثاني / مكان ومنصة العرض \\
\hline$\cdot, 91$ & المحور الثالث / الإضاءة \\
\hline$\cdot, \wedge 9$ & المحور الرابع / الخلفية الصوتية \\
\hline$\cdot, 90$ & ل المحور الخامس / المعروضات \\
\hline •,ar & المحور السادس / عارضة الأزياك \\
\hline$\cdot, A v$ & المحور السابع / ضبط شكل الأزياء على العارضة \\
\hline$\cdot, 91$ & المحور الثامن / الشكل العام للعرض \\
\hline$\cdot, 9 \mathrm{r}$ & معامل الثبات الإجمالي \\
\hline
\end{tabular}

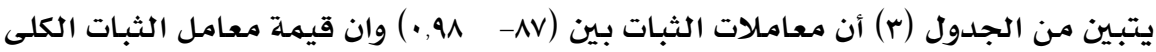

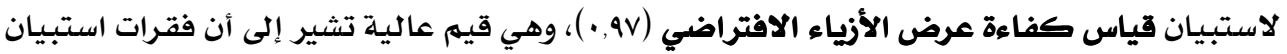

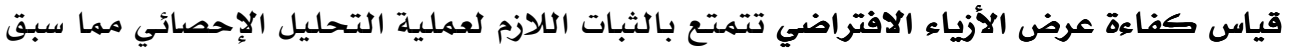

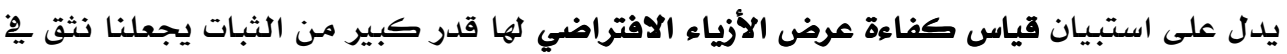
النتائج المترتبة على هذه الأبيان قياسل ثانياً: إعداد مقياس اتجاه الطالبات للعرض الافتراضي المنفذ باستخدام البرامج الثلاثية الأبعاد: أ- تحديد الهدف من المقياس: هدف مقياس الاتجاه إلى قياس اتجاه الطالبات يْ قسم الملابس والنسيج بكليات الاقتصاد

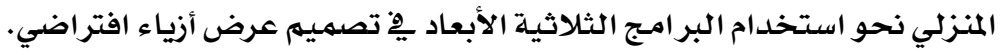
ب- صياغة عبارات المقياس: وبنـاء على مـا سـبق تم صـياغة (r) ) عبـارة لمقيـاس الاتجــاه نحـو العـرض الافتر اضـي المنفـذ

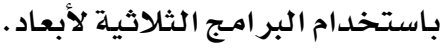


صدق مقياس اتجاه الطالبات للعرض الثلاثي الأبعاد:

من أجل التأكد من صدق مقياس اتجاه الطالبات للعرض الثلاثي الأبعاد المنفذ باستخدام البر امج الثلاثية الأبعاد أنتاد

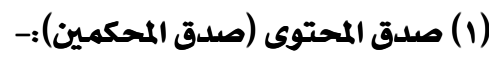

بعد الانتهاء من إعداد مقياس الاتجاه للطالبات وبناء فقراته، تم عرضه مِّْ صورته الأولية

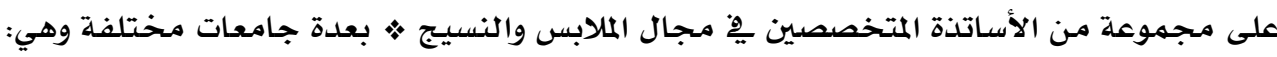

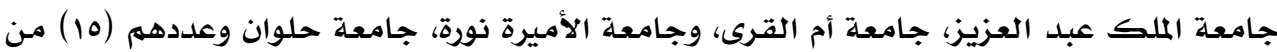

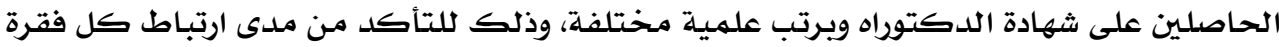

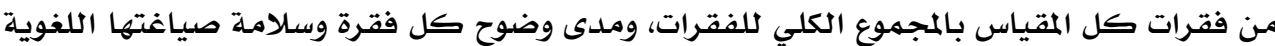

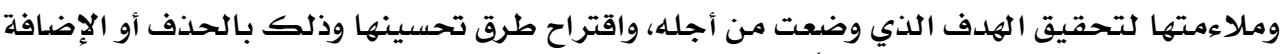

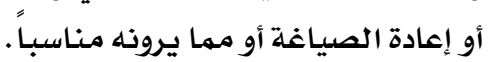
وفيما يلي نسب الاتفاق بين المحكمين فيما يخص بنود تحكيم أدوات الدراسـة:-

جدول (4) ذسب الاتفاق بين المحكمين لبنود التحكيم لمقياس اتجاه الطالبات (عدد المحكمين = 15 محكم)

\begin{tabular}{|c|c|c|c|c|}
\hline \multicolumn{3}{|c|}{ مقياس الاتجاه للطالبات } & \multirow{2}{*}{ بنود التحكيم } & \multirow{2}{*}{ a } \\
\hline نسبة الاتفاق & عدد مرات الاختلاف & عدد مرات الاتفاق & & \\
\hline $1 .$. & - & 10 & قياس البنود لآراء الطالبات & 1 \\
\hline $9 r, r$ & 1 & $1 \mathfrak{\varepsilon}$ & وضوح البنود & $r$ \\
\hline $1 \cdots$ & - & 10 & الصحة اللفوية للأسئلة & $r$ \\
\hline Ar & $r$ & ir & مقترحات من وجهة نظركم & $\xi$ \\
\hline$\% 90$ & & لبنود & & \\
\hline
\end{tabular}

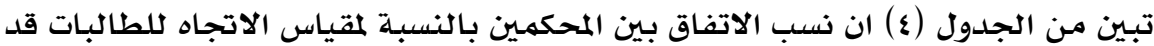

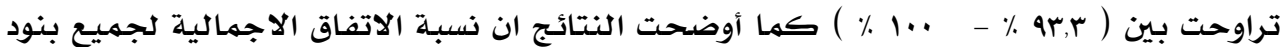

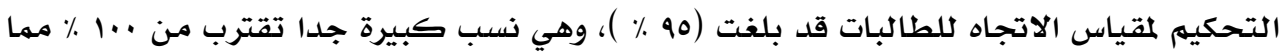

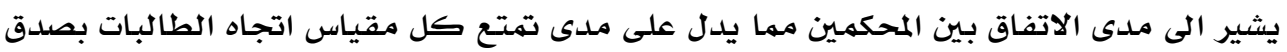
المحكمـين. صدق الاتساق الداخلي لمقياس اتجاه الطالبات: تم التأكد صدق الاتساق الداخلي لمقياس اتجاه الطالبات من خلال حساب معاملات

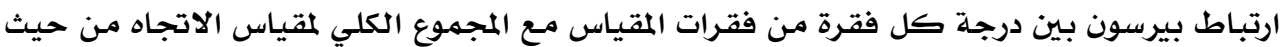
أوضحت نتائج التحليل الإحصائي أن معاملات الارتباط درة كنانت على النيات النحو التالي:- 
جدول (5) نتائج معاملات ارتباط بيرسون بين درجة كل عبارة وبين الدرجة الكلية للمقياس

\begin{tabular}{|c|c|c|}
\hline 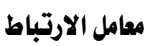 & بنود الاستبيان & 今 \\
\hline$* *, \wedge \uparrow$ & أويلد استخدام البرامج الثلاثية الأبعاد لتصميم عرض أزياء افتزاضي & 1 \\
\hline$* *, 91$ & أجد صعوبة في عرض أزيائي التي قد صمتها _على أرض الواقع & $r$ \\
\hline$* *_{\bullet}$, Av & أشعر بالحماس لدراسة عرض الأزياء الافتراضي باستخدام البرامج الثلاثية الأبعاد & $r$ \\
\hline$* *, q$ & أشعر بالرغبة في معرفة البرامج المستخدمة في تصميم عرض الأزياء الافتراضي الثلاثي الأبعاد & $\varepsilon$ \\
\hline$* *_{,}, \mathrm{\vee} \wedge$ & لفة البرنامج المستخدم في عرض الأزياء واضحة مناسبة لي & 0 \\
\hline$* *, \wedge 0$ & الدراسة بمساعدة البرامج الثلاثية الأبعاد يعزز أدائي في الجانب المهاري & 1 \\
\hline$* *, 9$. & الدراسة بعساعدة البرامج الثلاثية الأبعاد يعزز أدائي من الجانب المعرفي & 7 \\
\hline$* *_{\bullet}$, Ar & أستطيع من خلال استخدام البرامج الثلاثية الأبعاد تصميه عرض أزياء يعكس مـا تعلمته في مقـرر عـرض & 8 \\
\hline$* *, 90$ & أنجذب لفكرة تصميه عرض أزياء للمصانع المختصة بصناعة الملابس & 9 \\
\hline$* *, \mathrm{v \varepsilon}$ & قد أجد صعوبة في تصميه عرض أزياء باستخدام البرنامج الثلاثي الأبعاد & 10 \\
\hline$* *$, va & أستطيع من خلال برنامج عرض الأزياء الافتراضي أن أكتشف أخطائي وأعدلها في عرض الأزياء الواقعي & 11 \\
\hline$* *_{*}, 91$ & ينمي العرض الافتراضي مهاراتي في تصميي الأزياء & ir \\
\hline$* *, 9$ & من وجهة نظرك هل برنامج Marvelous Designer3 هو أكثر الـبرامج مناسبةً لتصميه عـروض & 13 \\
\hline
\end{tabular}

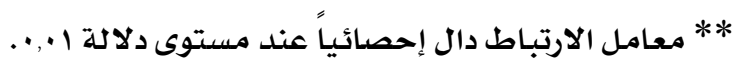

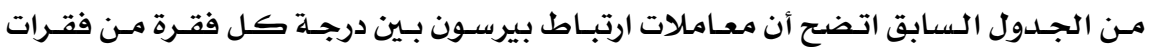

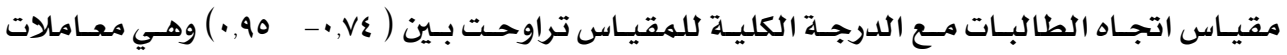

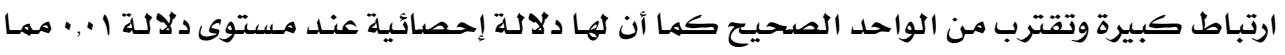

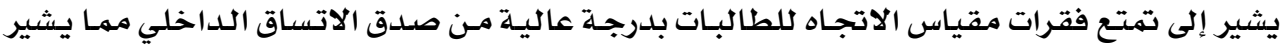

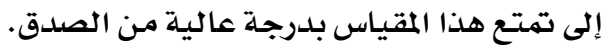$$
\text { ثبات مقياس الاتجاه للطالبات: }
$$

تم التأكـد مـن ثبـات مقيـاس الاتجـاه للطالبـات مـن خـلال حسـاب ثبـات الاتساق الداخلي

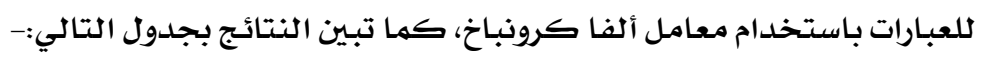

\begin{tabular}{|c|c|}
\hline معامل الثبات & مقياس الاتجاه للطالبات \\
\hline •, 9r & معامل الثبات الإجمالي لمقياس الاتجاه للطالبات \\
\hline
\end{tabular}
جدول (6) نتأبج معاملات الثبات الفا كرونباخ لمقياس الاتجاه للطالبات 
مجلة بحوث التربية النوعية - علد

يتبين من الجدول (ج) قيمة معامل الثبات الكلى لمقياس الاتجاه للطالبات (به,·)، وهي

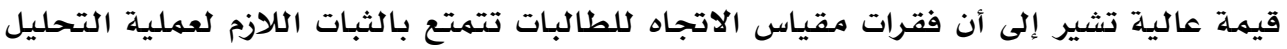

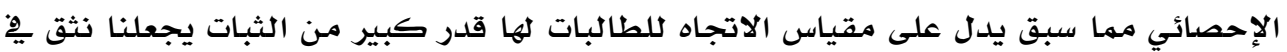
النتائج المترتبة على هذه الأداة

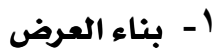

اعتمـدت الدراسـة على تصميهم عرض الأزيـاء الثلاثي الأبعـاد على البر امـج ثلاثيـة الأبعـاد كarvelous Designer 3 للعرض خطوات تصميم منصة عرض الأزياء: تم تصميم منصدة عرض الأزياء عن طريق عن طريق الدخول لموقع

http://www.optitex-dynamiccloth.com/FreebieDownload08.php

واستخدام برنامج 3D MAX لتصميم الشكل النهائي للمنصة .

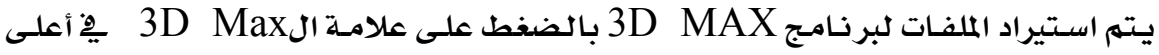
الشاشة واختيار الأمـر Import.

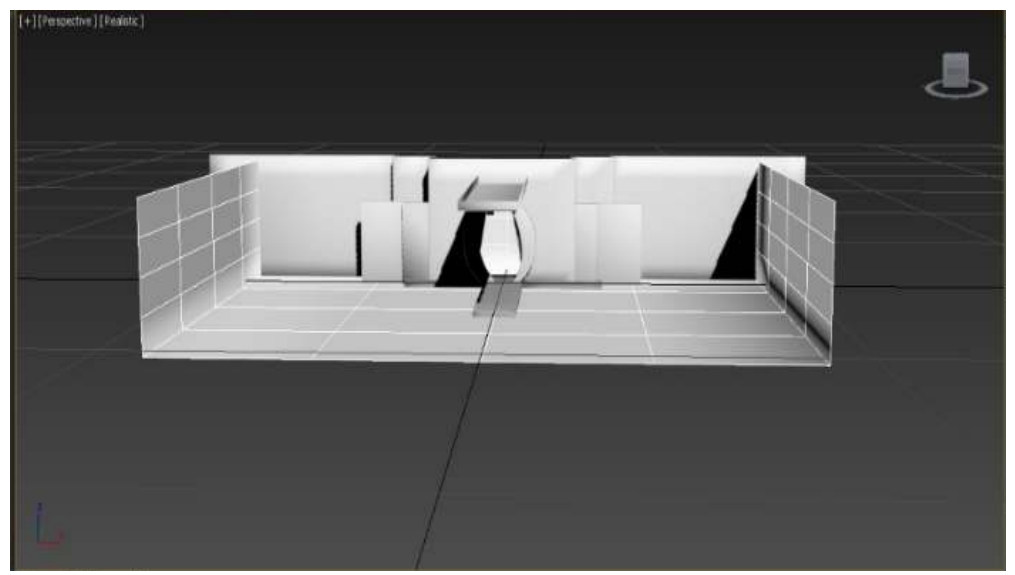

الشكل (1) منصة عرض الأزياء

وضع الكاميرا والإضاءة أولا: الكاميرا: Create> Cameras>Target . سنختار الكاميرا الموجهة. 


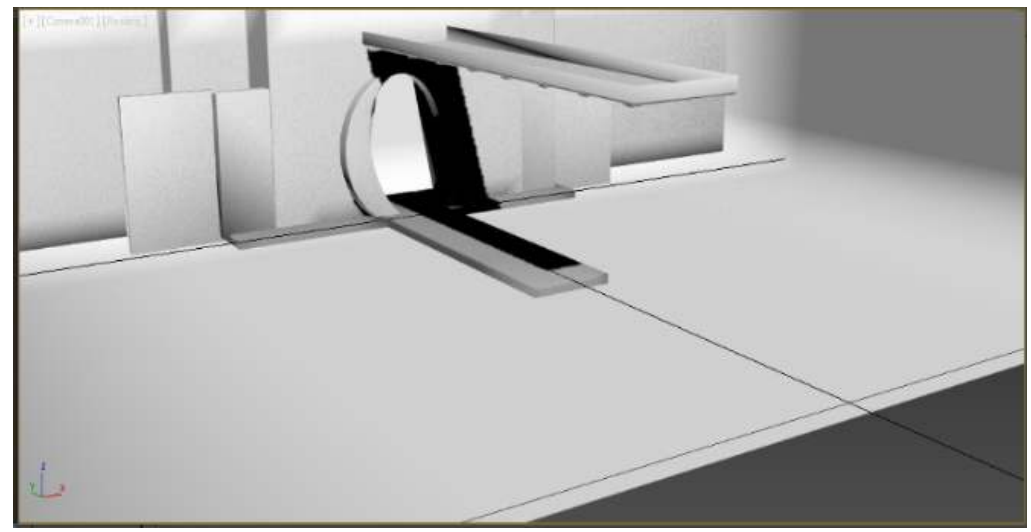

الشكل (r) تعيين الكاميرا الموجهة على منصة العرض .

ثانيا: الإضاءة:

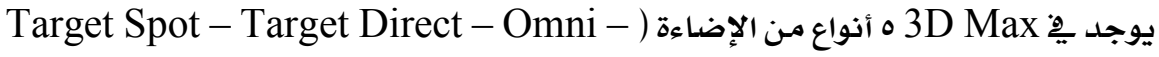

(Free Spot - Free Direct

نبدأ بإضافة الإضاءة، ويوجد نوعين من الإضاءة إمَّا أن تكون Standard أو Photometric

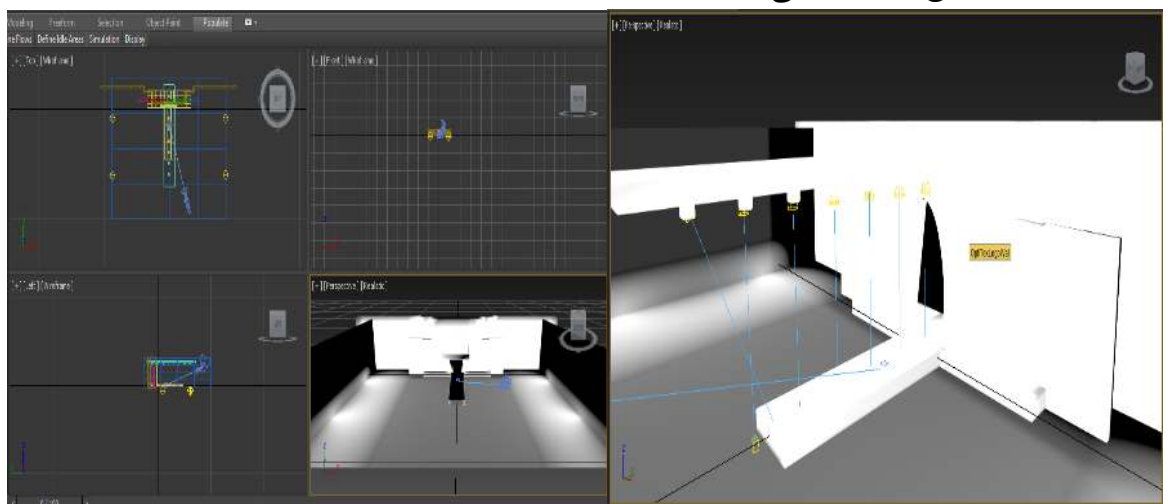

الشكل (r) اضافة الإضاءة على منصة العرض

ثالثا: الخامـات:

كل ما نريد عمله الآن هو عمل اكساء لمنصة العرض من خامات مختلفة. وهذه الخامات

متوفرة كصورة ويمكن اختيار أي صورة متوفرة لديك، نختار الصورة التي نريدها وهي خداء

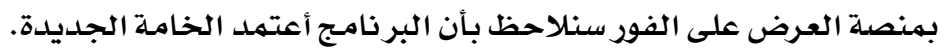



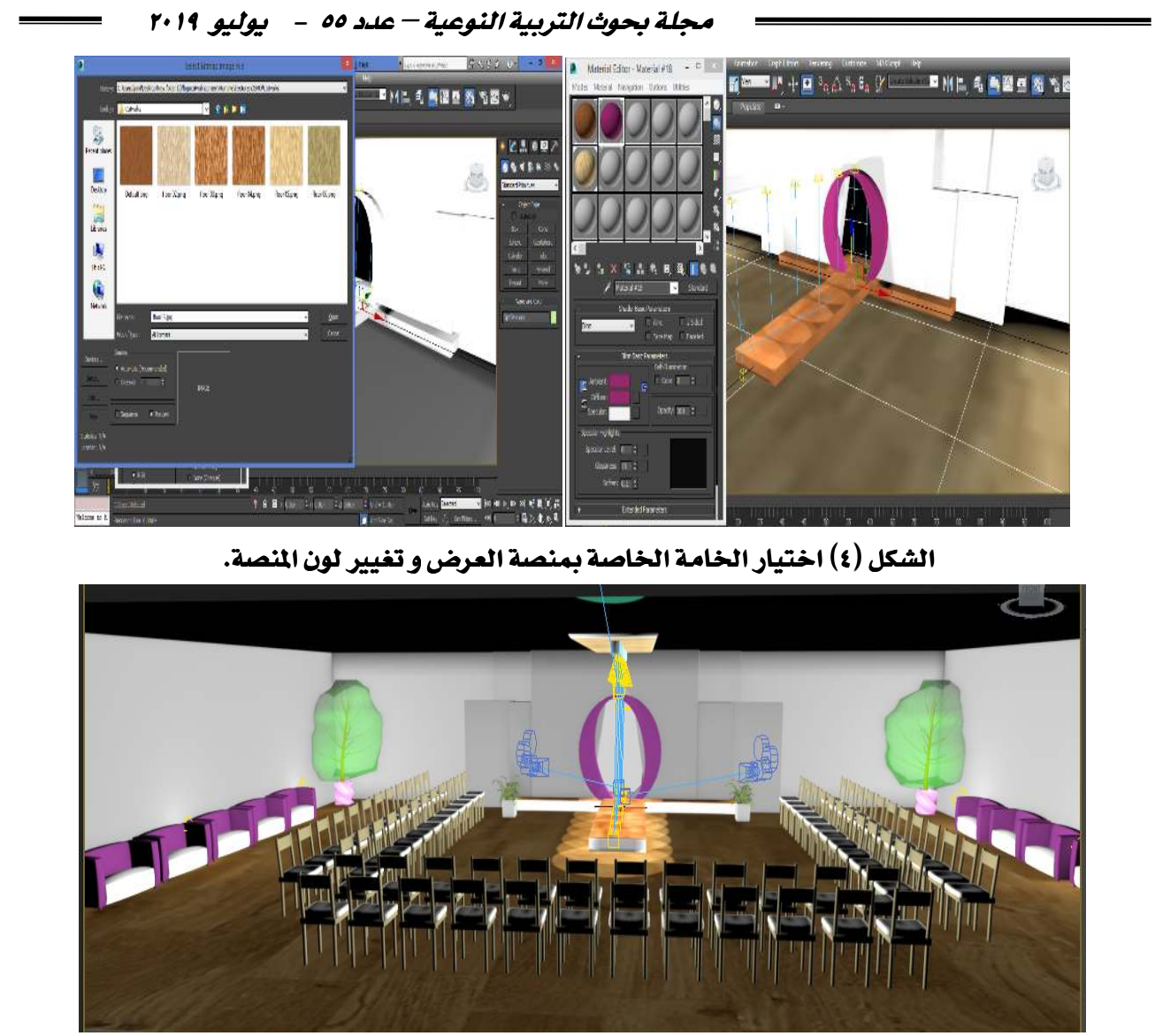

الشكل (0) الشكل النهائي لمنصة العرض

إدخال العارضة والأزياء:

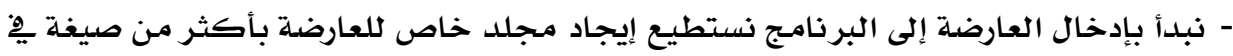
صفحة البرنامـج على الرابط التالي:

https://www.marvelousdesigner.com/community/forum/TheCommons/3263 - بالعودة إلى برنامـج ال 3D Max نقوم باستيراد العارضة بشرط أن تكون حركة العارضة نفس

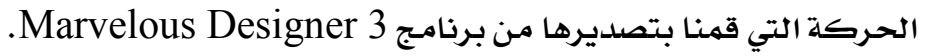

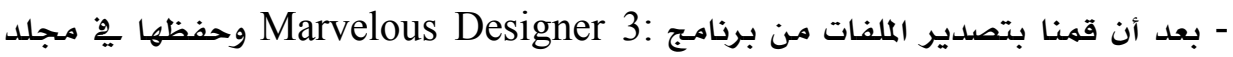

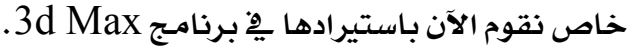




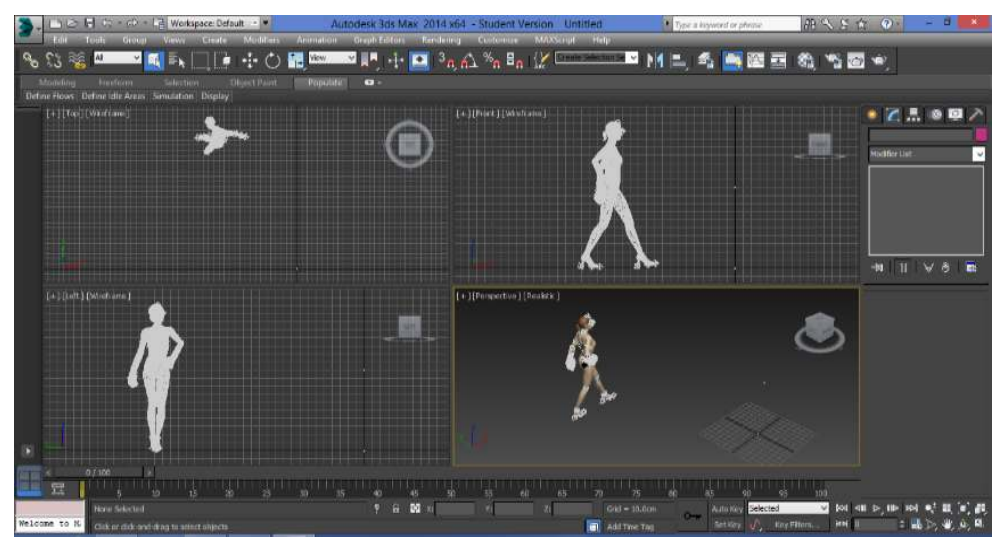

الشكل (ף) شكل العارضة المختارة.

- نختار أي ملف نريد من ملفات الأزياء التي تم تصميمها وتصديرها بشرط أن يكون بصيغة

.Obj

يظهر معنا الزي المراد تلبيس العارضدة به من القائمة الجانبيه نختار Modifier List ثم

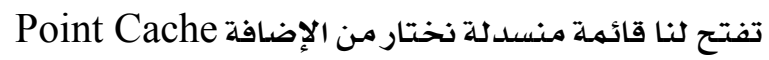

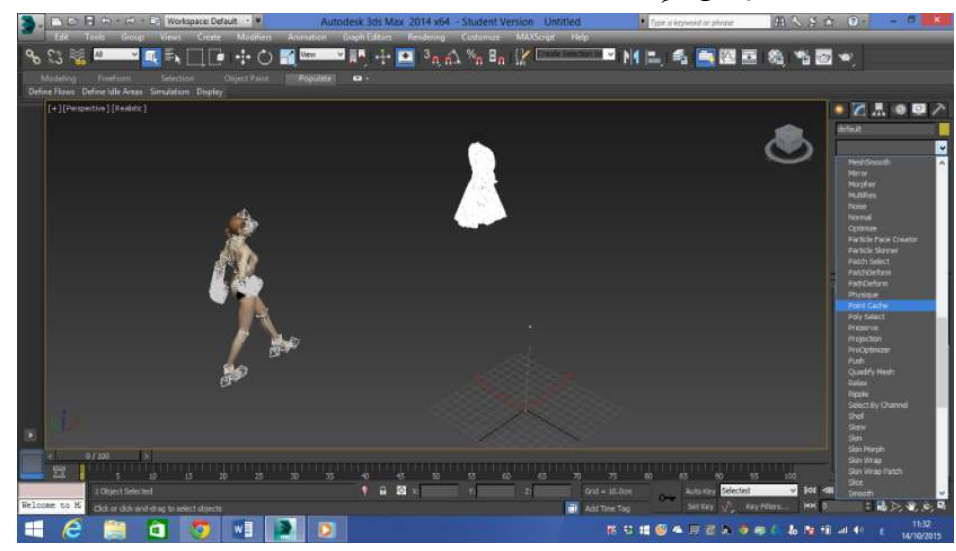

$$
\text { هكل (v) اختيار الزي المراد تلبيس العارضة به. }
$$

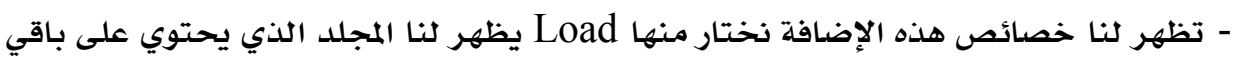

$$
\text { ملفات الأزياء. }
$$

- نختار الملف الحركة الخاص بالزي الذي اخترناه مثلا إذا اخترنا الزي رقم ه نضيف الملف رقم الماء 0

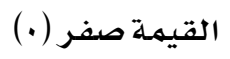




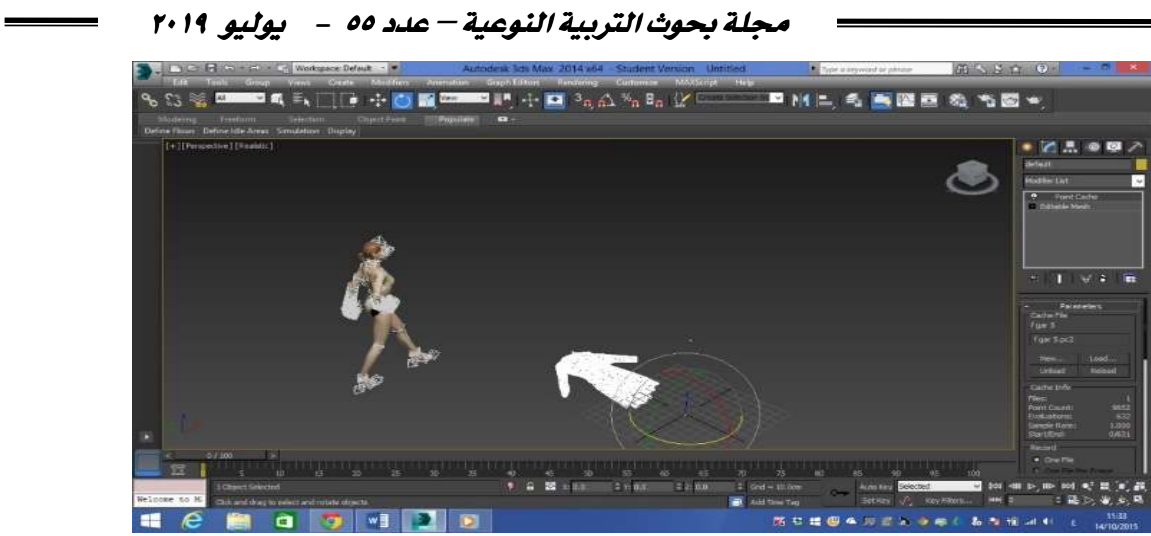

$$
\text { شكل (^) إحداثيات مكان الزي عند اختيار ملف الحركة الخاص به. }
$$

- من القائمة نختار الأيقونة المحددة Select and Rotate ونتزل لشريط المحاور يِّ الأسفل

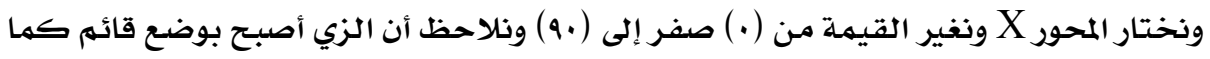

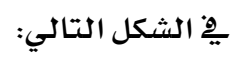

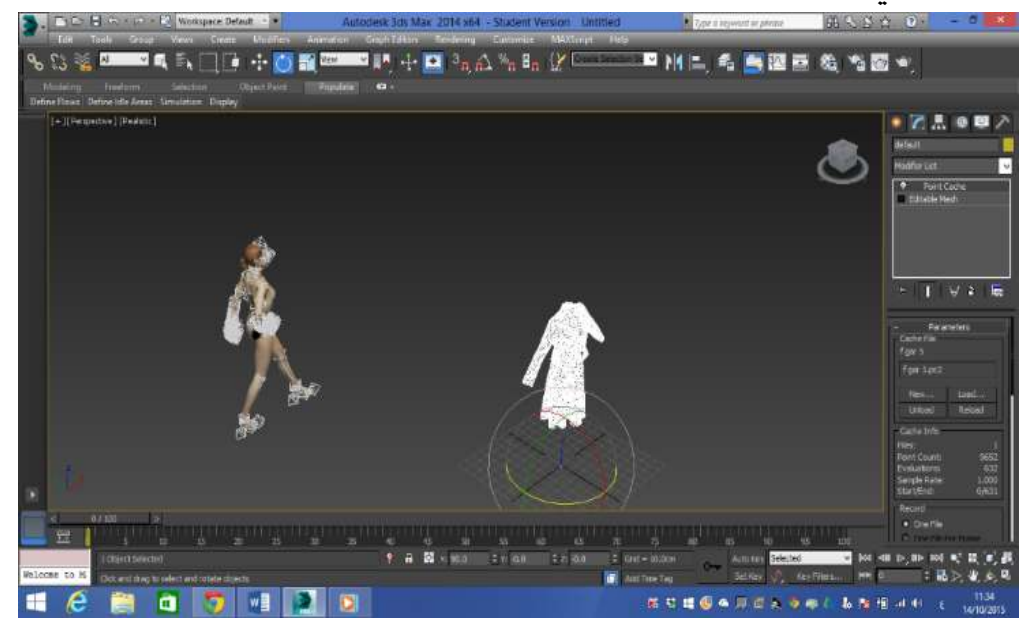

$$
\text { شكل (9) وضع الزي عند تغيير المحور X إلى .9. }
$$

نبدأ بتغيير الوقت المستغرق للحركة حتى تتوافق حركة الزي مـع حركة التهري

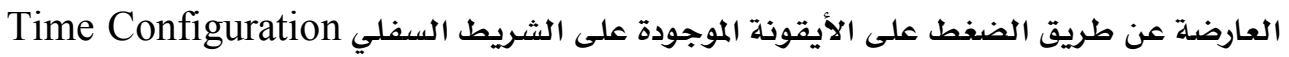

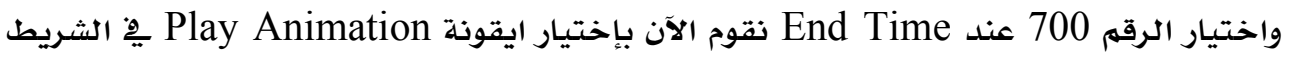

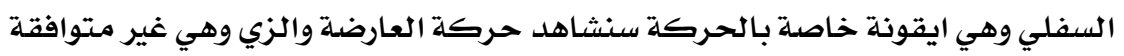




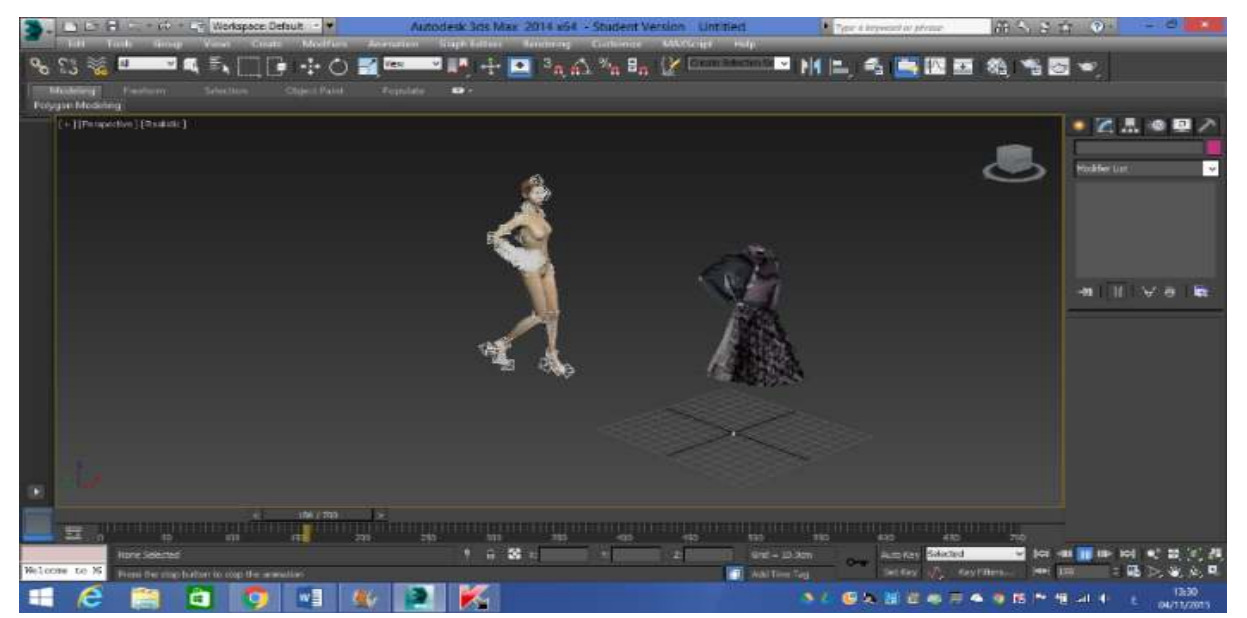

شكل ( ـ ) عرض حركة العارضة والزي من خلال ايقونة Play Animation.

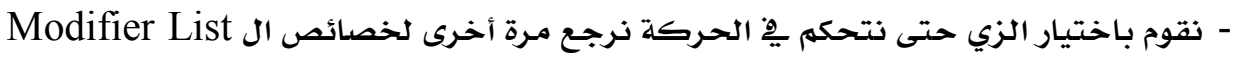

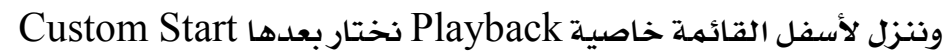

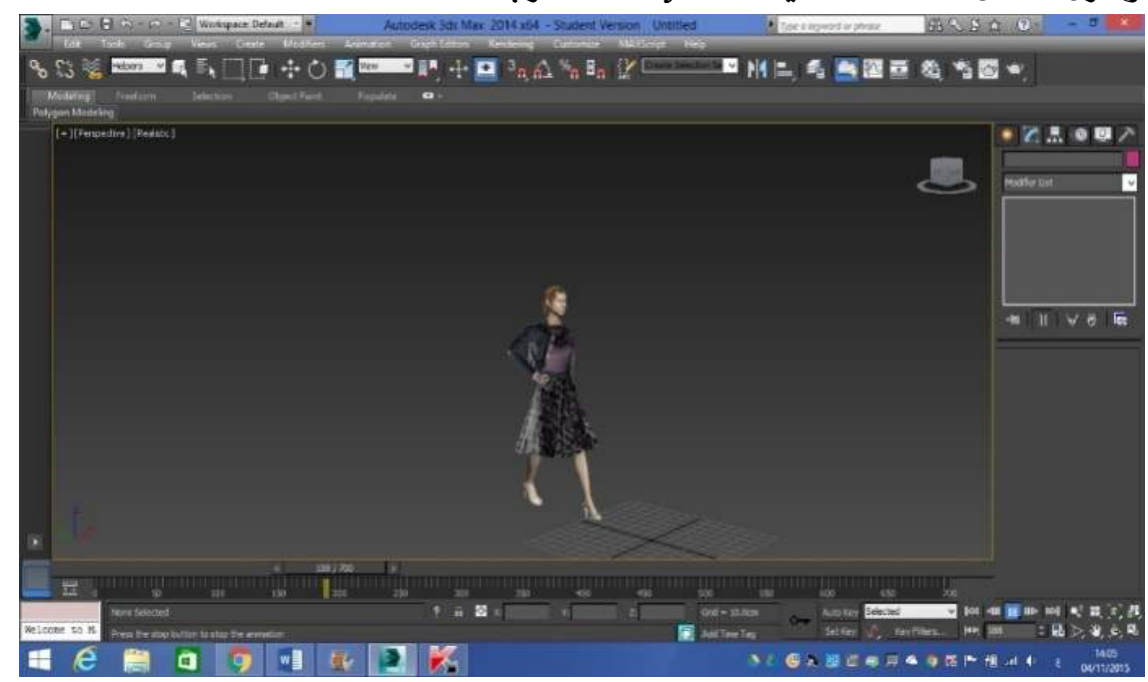

\section{شكل (11) تلبيس العارضة .}

- نبدأ إدخال المنصة على العارضة من Mmport نختار Merge وهي خاصدة بإضافة الملفات

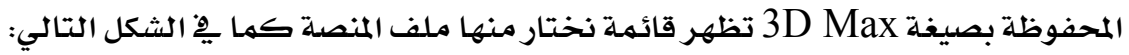




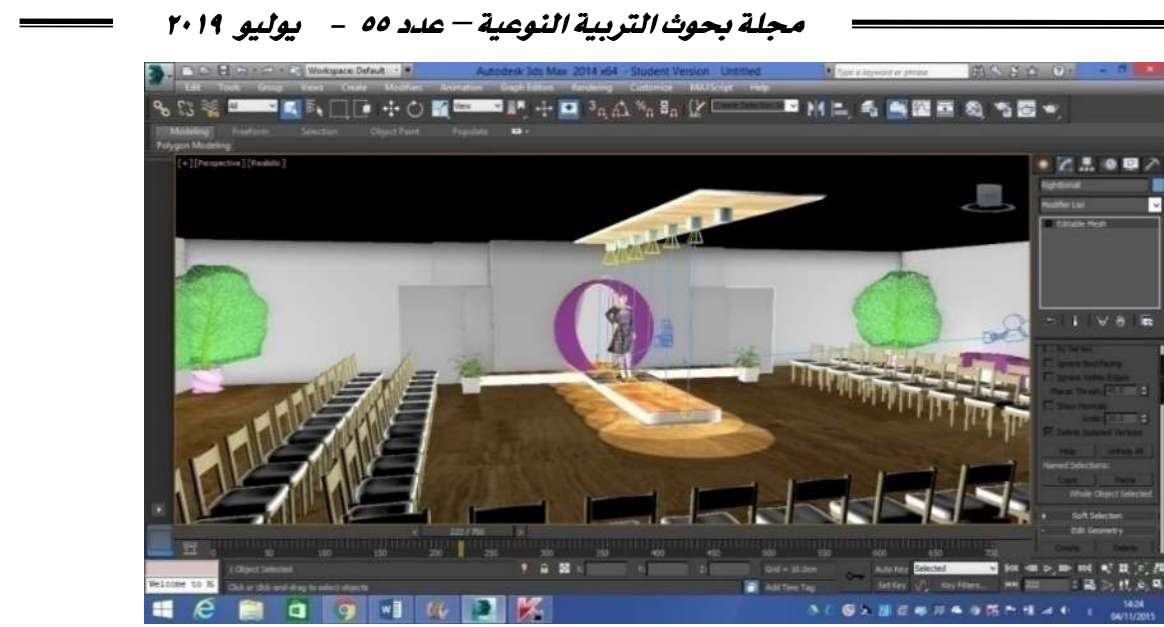

شكل (r) الشاشة بعد إدخال المنصعة على العارضة.

- نقوم بتشغيل حركة العارضـة لنـرى توافقها مـع منصدة العرض هنا العمل بشكل النهائي نقوم الآن بحفظ العمل بصسيغة فيديو مناسبـة لنا:

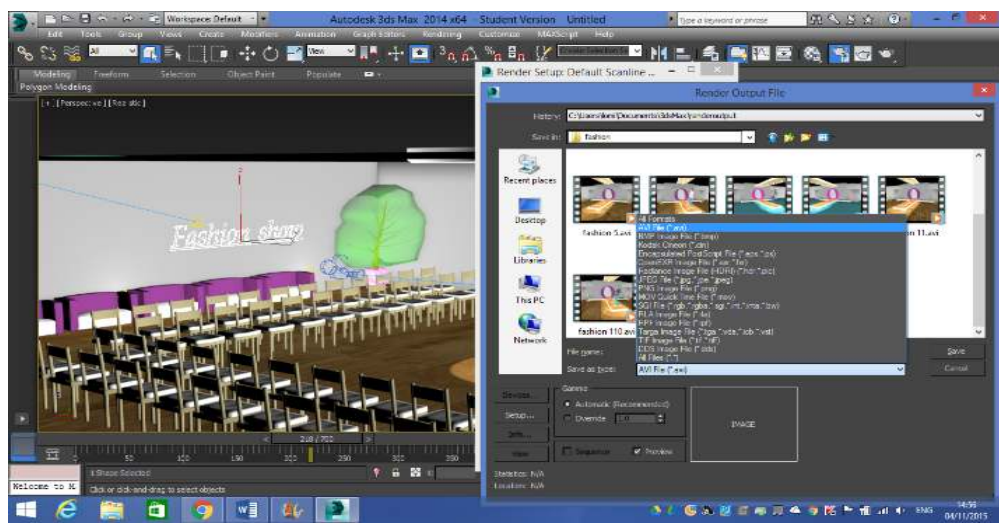

شكل (Ir) حفظ الملف بصيغة الحفظ AVI File.

- نختار بعد حفظ الملف Render تتهم بعدها حفظ شرائح العهل من الرقم 1.1 إلى الرقم 350

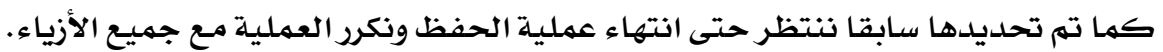

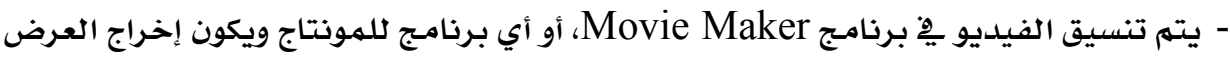

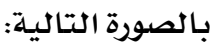


可

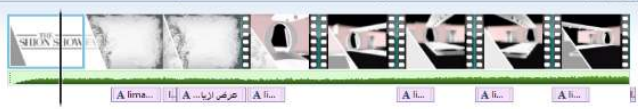

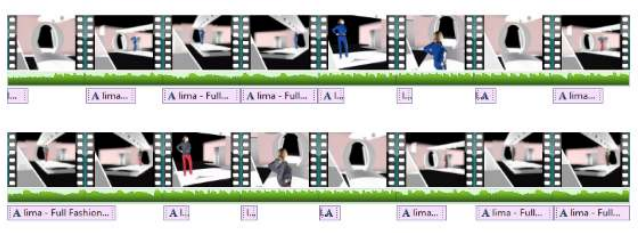

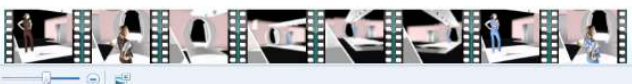

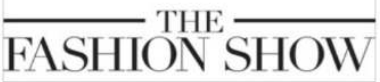

شكل (\&) أنسيق الفيديو ِِِ برنامج

النتائج Results

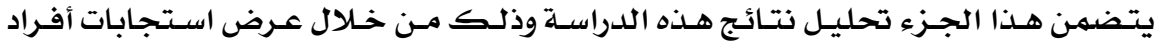

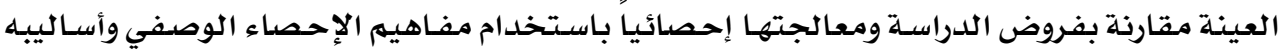

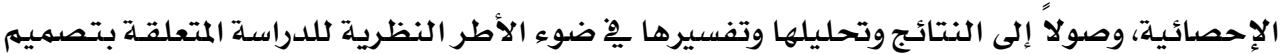

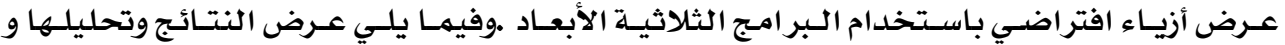
تفسيرها :

\section{التحقق مز صحة الفرض الأول :}

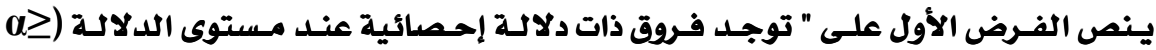

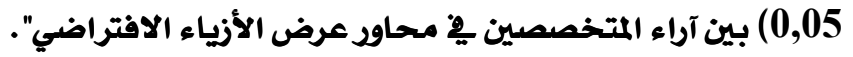

للتأكد من صحة الفرض السابق تم استخدام اختبار كروسكال واليز وهو احد

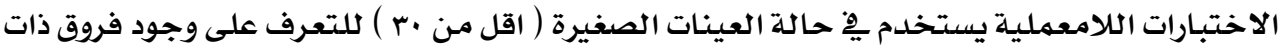

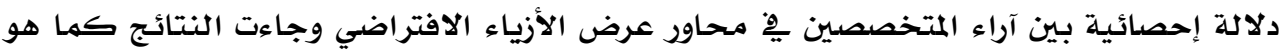
موضح حِّ الجدول التالي: 
جدول رقم (v) نتائج تحليل التباين للفروق بين آراء المتخصصين فِ محاور عرض الأزياء الافتراضي

\begin{tabular}{|c|c|c|c|c|}
\hline 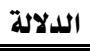 & قيمة الدلالة & 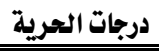 & مربع كاي & المحور - المو \\
\hline 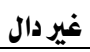 & 0.42 & 2 & 1.74 & المحور الأول / موضوع وعنوان العرض \\
\hline 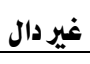 & 0.92 & 2 & 0.16 & المحور الثاني / مكان ومنصة العرض \\
\hline غير دال & 0.64 & 2 & 0.88 & المحور الثاث / الإضاءة \\
\hline 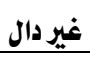 & 0.98 & 2 & 0.04 & المحور الرابع / الخلفية الصوتية \\
\hline 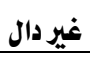 & 0.94 & 2 & 0.12 & المحور الخامس / المعروضات \\
\hline 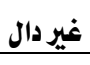 & 0.89 & 2 & 0.24 & المحور السادس / عارضة الأزياء \\
\hline 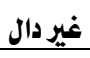 & 0.69 & 2 & 0.73 & المحور السابع / ضبط شكل الأزياء على العارضة \\
\hline 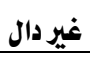 & 0.66 & 2 & 0.84 & المحور الثامن / الشكل العام للعرض \\
\hline 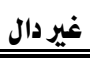 & 0.95 & 2 & 0.11 & إجمالي الاستبيان \\
\hline
\end{tabular}

$$
\text { تشير نتائج الجدول إلى مايلي : }
$$

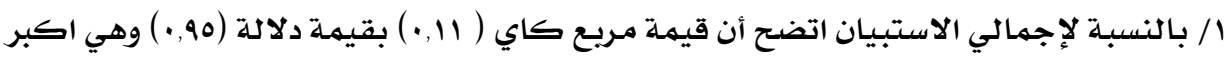

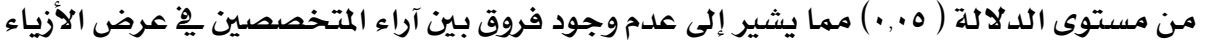

$$
\text { الافتراضي. }
$$

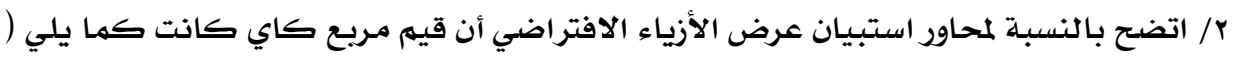
(ه)

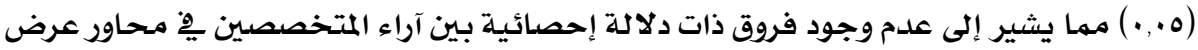

$$
\text { الأزياء الافتراضي. (مها يشير إلي }
$$

لقد أثبتت العمليات الإحصائية السابقة أنه لا توجد فروق ذات دلاله إحصائية بين آراء

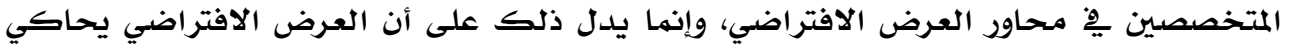

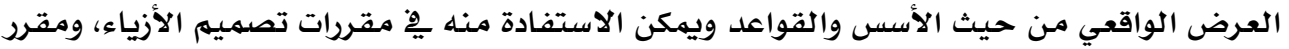

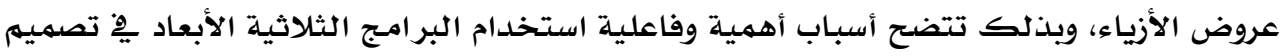
عرض أزياء افتراضي. وقد اتفقت النتائج مـع دراسـة إسماعيل ( • +r) إلى أن الصورة عالية الجودة والرسوم ثلاثية

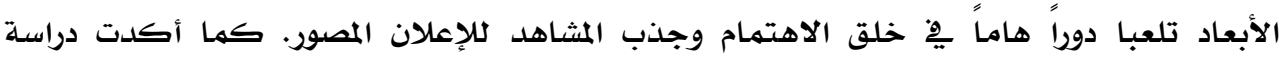

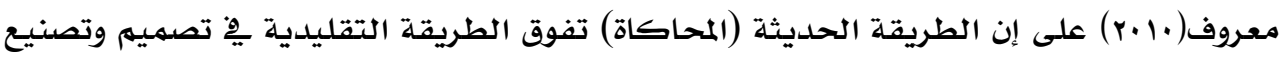
الملابس معروب

وبناءً على هذه النتيجة يتم رفض الفرض السابق وقبول الفرض الصفري التالي:-

لا توجد فروق ذات دلالة إحصائية عند مستوى الدلالة (a ه ه .,.) بين آراء المتخصصين فِ 


\section{בصميه عرض أزياء /فتراضي باستخلام البرامج الثلاثية الأبعاد \\ التحقق من صحة الفرض الثاني :}

ينص الفرض الثاني على أنه "توجد فروق ذات دلالة إحصائية عند مستوى الدلالة (ألاءل)

$$
\text { ه., •) بين آراء الطالبات يْ محاور عرض الأزياء الافتراضي". }
$$

للتأكد من الفرض السابق تم استخدام اختبار تحليل التباين أحادى للتعرف على الفروق

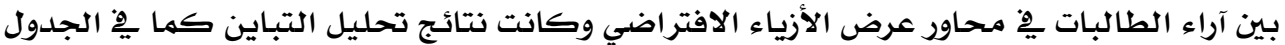

جدول (^) نتائج تحليل التباين للفروق بين آراء الطالبات فِ محاور عرض الأزياء الافتراضي

\begin{tabular}{|c|c|c|c|c|c|c|}
\hline الدلالة & قيمة الدلالة & قيمة (ف) & متوسط المربعات & درجات الحرية & مجموع المربعات & مصدر الاختلاف \\
\hline \multirow{3}{*}{ غير دال } & \multirow{3}{*}{$\cdot, 1 \varepsilon$} & \multirow{3}{*}{$1, \wedge v$} & $\cdot, 7.1$ & 2 & •,rr+1 & بين المجموعات \\
\hline & & & •,rrI & 46 & $1 \xi, V Y r$ & داخل المجموعات \\
\hline & & & & 48 & $0,9 \vee 7$ & الاحمالي \\
\hline
\end{tabular}

من الجدول السابق يتضح أن قيمة (ف) المحسوبة بلغت (I,AV) بقيمة دلالة (عا,•) وهي اكبر من مستوى الدلالة (ه... ) مها يشير إلى عدم وجود فروق ذات دلالة إحصائية بين آراء الطالبات

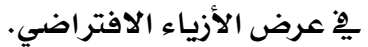

$$
\text { يتضع من الجدول (0- r ) الآتي: }
$$

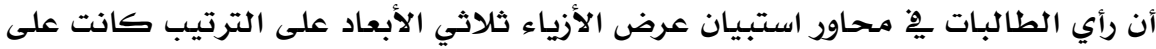

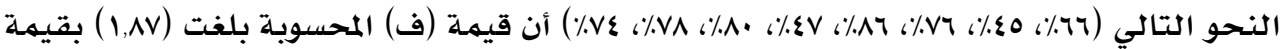

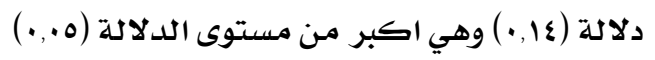

لقد أثبتت العمليات الإحصائية السابقة على أنه لا توجد فروق ذات دلاله إحصائية بين آراء

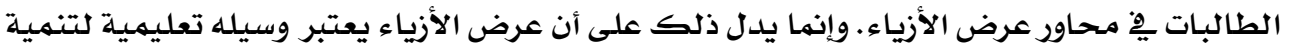

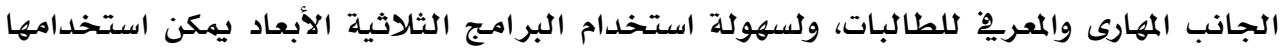
لتخدم قطاع الصناعة وخاصلة صناعة الملابس.

وقد اتفقت نتائج هذا الفرض مـع دراسة متولي (rا.r) على أن استخدام عرض الأزياء

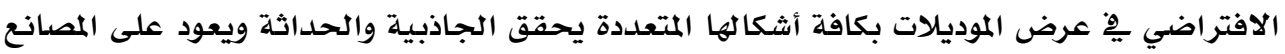

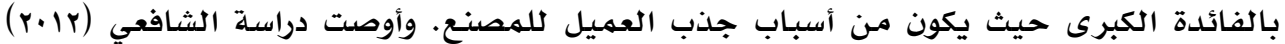

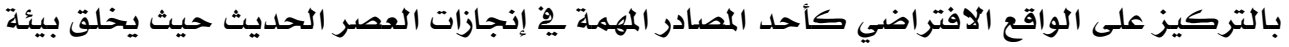

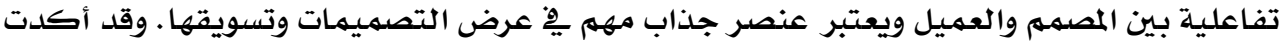

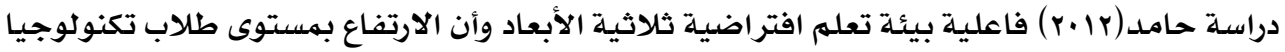

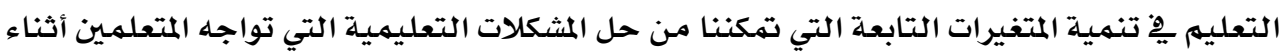

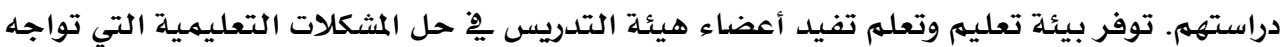
الطلاب أثناء دراستهم لوصر بيتهاء 
وبناءً على هذه النتيجة يتم رفض الفرض السابق وقبول الفرض الصفري التالي: -

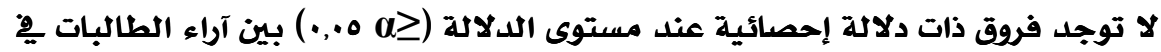

$$
\text { محاور عرض الأزياء الافتراضي. }
$$

التحقق من صحة الفرض الثالث :

ينص الفرض الثالث على " يوجد اتجاه إيجابي للى الطالبات نحو استخدام عروض الأزياء

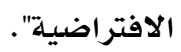

للتأكد من الفرض السابق تم حساب المتوسط الحسابي والانحراف المعياري لمقياس

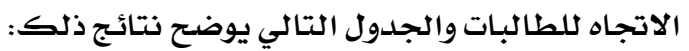

جدول (ه) المتوسط الحسابي والانحراف المعياري لآراء الطالبات نحو استخدام عروض الأزياء الافتراضية

\begin{tabular}{|c|c|c|}
\hline الانحراف المعياري & المتوسط الحسابي & حجم العينة \\
\hline •, ro & 2.57 & 50 \\
\hline
\end{tabular}

معيار الحكم على الاتجاه من خلال المتوسط الحسابي:-

ا. إذا وقعت المتوسط الحسابي بين (1- 17, 1) يكون اتجاه الطالبات نحو استخدام عروض الأزياء

$$
\text { الافتر اضية سلبي. }
$$

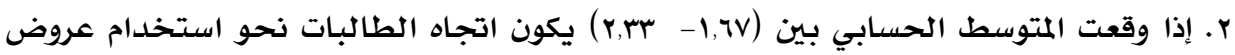

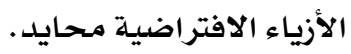

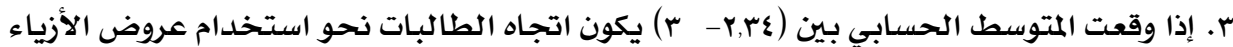

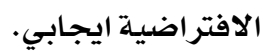

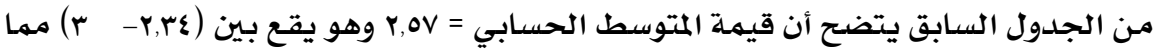

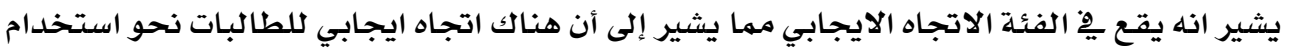
عروض الأزياء الافتر اضية.

$$
\text { مما سبق يتهم قبول الفرض التالي: }
$$

"يوجد اتجاه إيجابي لدى الطالبات نحو استخدام عروض الأزياء الافتراضية".

\section{التوصيات Recommendations}

من خلال هذا العرض لنتائج الدراسة يوصي البحث بالتالي :

• ضرورة التوسع والدراسة يِّ مجال استخدام النظم ثلاثية الأبعاد يِّ تصميهم وتنفيذ الأزياء. • ضرورة التوسع ِِّ دراسة البرامـج الثلاثية الأبعاد ِِّ قسم الملابس والنسيج بكليات الاقتصاد

$$
\text { المنزلي. }
$$

• عمل دورات تدريبيه لبر امج التصميم ثلاثية الأبعاد للمهتمـين والمختصين يِّ مجال الأزياء. 


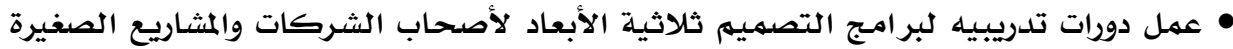

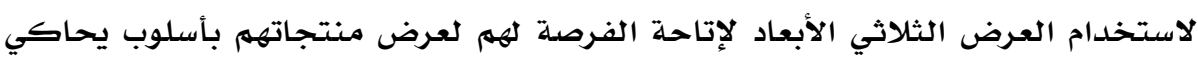
طبيعة المنتجات الملبسية.

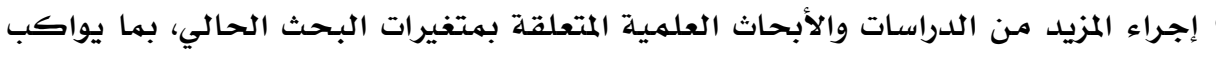

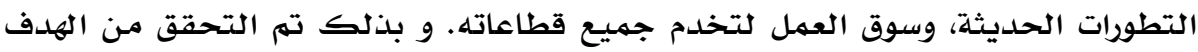

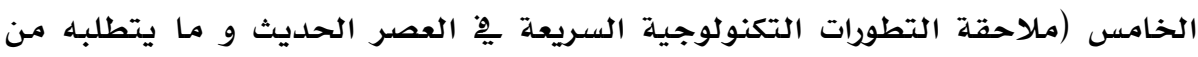
تعديلات سلوكية و مهارية و تنمية قدرات.

\section{المراجع References:}

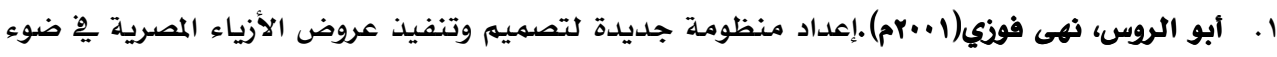

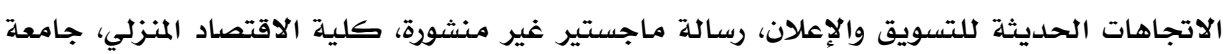
المنوفية، مصر.

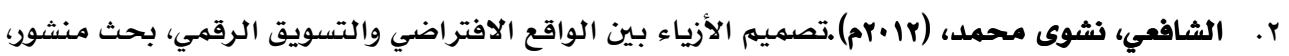

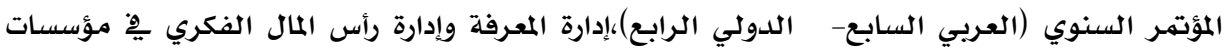

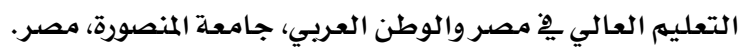

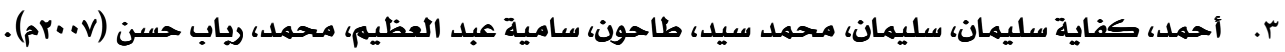

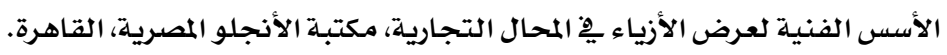

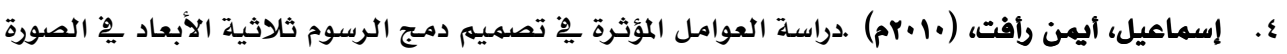

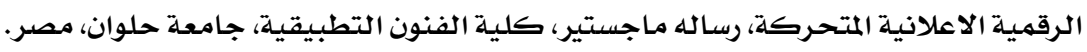

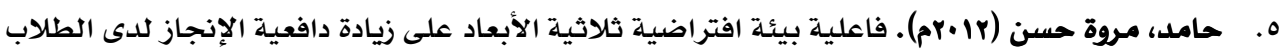
واتجاهاتهم نحو البيئة الافتراضية.

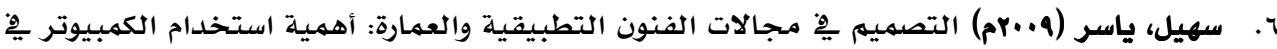

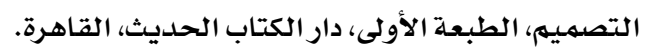

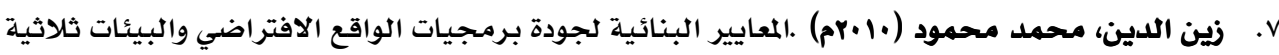

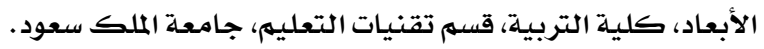

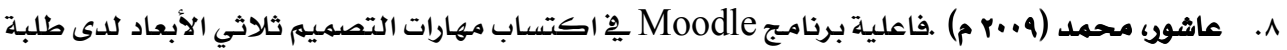

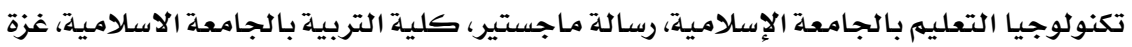

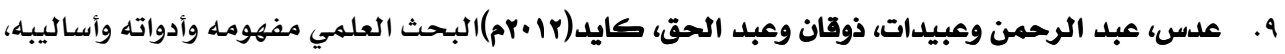

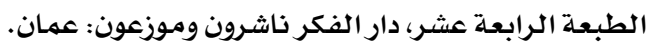

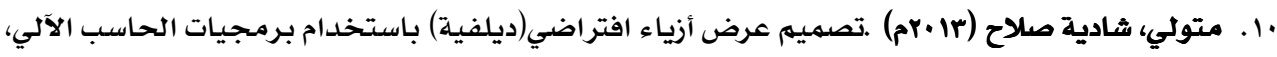

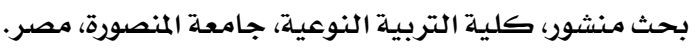


$\overline{\underline{ }}$

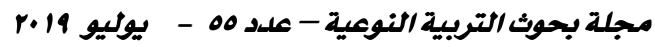

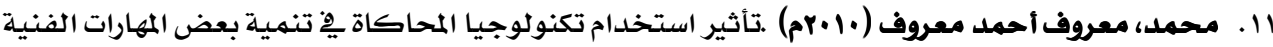

لبعض مواد تصميه وتصنيع الملابس لدى طلاب الجامعة المتخصصين، مجلة علوم وفنون - دراسات

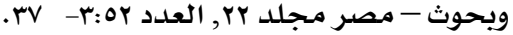

12. Aydoğdu G, Yeşilpınar S,and Erdem D (2017). Evaluation of ThreeDimensional Visual Perception of Garments. J Fashion Technol Textile Eng. $5: 4$

13. Brown,E,Hobbs,M and Gordon,M(2008)A Virtual World Environment for Group Work, International Journal of Web-Based Learning and Teaching Technologies,3(1)1-2,URL.

14. Elizabeth Bye, Ellen McKinney, (2010). "Fit analysis using live and 3D scan models", International Journal of Clothing Science and Technology, Vol. 22 Issue: $2 / 3$, pp.88-100.

15. Drake, Frances Mary, Janice Harrison, Spoone, and Harbert, Greenwald (1992).Retail Fashion Promotion \&Advertising, Macnillan Puplishing Company.

16. Jun Zhang, KyoungOk Kim, Masayuki Takatera, (2017). "Threedimensional garment-size change modelled considering vertical proportions", International Journal of Clothing Science and Technology, Vol. 29 Issue: 1, pp.84-95.

17. http://www.optitex-dynamiccloth.com/FreebieDownload08.php

18. https://www.marvelousdesigner.com/community/forum/TheCommons/3263 